\title{
Corporate Social Responsibility in Cameroon: Practices and Environmental Impact
}

\author{
Peter Fofuh ${ }^{1} \&$ Olawumi Dele Awolusi ${ }^{2}$ \\ ${ }^{1}$ Department of Business Administration, the Business School, University of Roehampton, London, UK \\ 2Department of Accounting and Finance, College of Economics and Management, Kampala International \\ University, Kampala, Uganda \\ peter.fofuh@roehampton-online.ac.uk, awolusi.olawumi@kiu.ac.ug
}

\begin{abstract}
The purpose of this study is to examine how CSR is practiced by local businesses and their influence on environmental protection and sustainable growth in Cameroon. Grounded on the stakeholder theory, a multi-method data collection tool was used to collect data for qualitative analysis. A thematic content analysis was approached was used in this study to examine the CSR practices of 20 local businesses in Cameroon. Findings from the study revealed that the concept of corporate social responsibility is relatively new and local corporations are not fully equipped to address the needs of their stakeholders. Also, environmental concerns and community issues were not areas of concern to companies when adopting CSR strategies. Additionally, government intervention to enforce existing laws and regulations on environmental and social issues was lacking. The study implies that by neglecting environmental concerns local businesses are endangering the environment and failing to plan for sustainable growth. Besides expanding knowledge about the level of CSR awareness and practice in Cameroon by exposing the limitations of local companies in adopting CSR and the laxity of the government in enforcing the relevant laws and legislation. It is recommended, that to plan for sustainable development and environmental protection, the government should be more proactive in upholding laws and regulations related to environmental protection and businesses, being more ethical in their daily practices. CSR policies should also be codified to encourage and compel businesses on the need for environmental protection by requesting businesses produce mandatory CSR disclosures.
\end{abstract}

Keywords: Corporate Social Responsibility, environmental protection, sustainable growth, thematic content analysis, Cameroon.

\section{Introduction}

This history of CSR in developing countries remains few and developed especially for African countries (Olayisade \& Awolusi, 2021; Visser, 2006). Visser (2006) in a review of literature spanning several years from 1995 to 2005 found out that of the 53 countries in the continent at the time there was existing literature for only 12 countries. This does not mean that CSR has not previously existed in developing countries. In many cases, there have been long-standing traditions of concerns for social justice that have been less visible internationally. Visser \& Macintosh (1998) contend that the condemnation of unethical business practices is common in most of these countries and dates back several thousands of years. An argument can be made that this is partly due to the history of colonialism, fraud and corruption generally linked to multinational business operations in developing countries (Odunlami, Awosusi, \& AwolusiI, 2017; Emezi, 2014). The recent trend of surrounding CSR is mainly because there has been much greater direct engagement by developing countries to address some social ills (Baxter, 2015). The question of business practices in developing countries has been closely linked to business ethics (Baxter, 2015; Verma, 2015).

As a matter of fact issues of sustainable development and environmental protection in developing countries characterized by poverty amid plenty, environmental negligence and poor management of resources lie at the heart of the CSR debate in developing countries. Several authors also argue that CSR Agenda in developing countries is highly influenced by the cultural context. This is because business practice in developing countries by foreign multinationals has always been seen to be predatory. To greenwash their activities foreign multinationals have often turned to philanthropy as a means of painting a good image of themselves. A study of CSR in the last decades in developing countries indicates that philanthropy tops most CSR initiatives with no regard for community engagement (Emezi, 2014; Visser 2006). To overcome the limitations of unscrupulous businesses practice, the current CSR discussion in developing countries is centered on the ethical approach which believes that businesses are accountable to all stakeholders (Verma, 2015; Omran, 2015). 
This has lent credence to an ethical approach to corporate social responsibility which contends that organizations should not only be concerned with their growth but should consider the interests of other stakeholders that can be affected by their organizational objectives (Fontaine, 2013; Omran, 2015). This line of thought can be linked to Freeman's (1984) normative stakeholder theory which contends that businesses are part of the social, economic and environmental ecosystems around them and as such they must take responsibility for the impact of their activities (Goel \& Ramanathan, 2014; Nikolova \& Arsić, 2017). Goel and Ramanathan (2014) argue that it is the responsibility of businesses to manage the way they do business to mitigate social and environmental challenges associated with their activities. Empirical studies indicate that such an approach does not only improves corporate community relationships but provides stakeholders holders with the opportunity to participate and take ownership of environmental concerns and sustainable growth (Oginni \& Omojowo, 2016; Baxter, 2015). However, empirical literature also suggests that most of the research done on CSR in developing countries has been mostly focused on the activities of multinationals with no input from local businesses (Sotamenou et al., 2013; Ndzi 2016). This has created a research gap where the CSR agenda in these countries is devoid of context as most CSR initiatives seem not to be adapted to local realities (Akwaowo \& Swanson, 2016).

Given that ethical concerns have been raised about how businesses operate in developing countries (Akwaowo \& Swanson, 2016; Oginni \& Omojowo, 2016), this study approaches the concept of CSR in Cameroon a country in sub-Saharan Africa from a local perspective to examine the influence of CSR policies in the country and their impact on the environment. Anchored on (Freeman, 1984) stakeholder theory, the author seeks to analyze and evaluate the CSR concept as understood and practiced by local businesses in Cameroon and the resulting impact on the environment. Available research indicates that corporate social responsibility can contribute enormously to community development (Emezi, 2014). While evidence indicates that CSR policies have produced positive results in the developed world, emerging countries are still lagging especially in Africa (Jamali \& Karam, 2018; Emezi, 2014). Existing literature points to the fact that Cameroon like many other developing countries has been slow in demanding greater responsibilities from business organizations (Jamali \& Karam, 2018). The agenda on corporate social responsibility in developing countries is mostly driven by philanthropic gestures most often from multinationals with no planned strategies to mitigate developmental issues (Emezi, 2014; Ndzi, 2016). Furthermore, the evolution of CSR in the continent has met with several obstacles that have been attributed to contexts.

Such as weak government institutions, gaps in public governance and corruption (Prates et al., 2015; Akwaowo \& Swanson, 2016; Ndzi, 2016). As a result, there are drawbacks and limitations in the manner in which CSR policies are implemented (Ndzi, 2016; Oginni \& Omojowo, 2016). Furthermore, empirical literature also suggests that there are no planned strategies to build sustainable business ventures that take into consideration the needs of local communities (Baxter, 2015). There are also suggestions that environmental concerns are not a concern and do not occupy a place of choice when implementing CSR policies (Goel \& Ramanathan, 2014). This has left local communities battling with issues of environmental degradation and corporate irresponsibility (Akwaowo \& Swanson, 2016; Oginni \& Omojowo, 2016). Fontaine (2013:110) contends that understanding the way a company views a phenomenon "alters the way the organization develops its value proposition and ultimately shapes how it employs this phenomenon in its business strategy". In other words, for local businesses to contribute to the CSR debate, it is important to review how they understand the CSR practice. The question then is how do local businesses in Cameroon view their role as partners in community development and sustainable growth? Secondly, how are CSR policies implemented in Cameroon and finally what is the impact of these policies on the environment? This study takes a look at the above-stated problems and tries to provide some answers.

As mentioned earlier the concept of CSR provides a medium for businesses to participate in mitigating some of the social and environmental challenges in the communities where they are implanted. This research work aims to examine the influence of CSR practice on environmental protection and sustainable growth in Cameroon. However, there are some specific objectives that the study wishes to explore which include:

- Examining how local businesses in Cameroon understand Corporate Social Responsibility.

- Examining how local businesses view their role in developing the communities in which they are implanted. 
- Examining what policies local businesses have developed towards CSR and how these policies have impacted the environment.

- Discuss why local businesses need to embrace CSR as a development tool that can help mitigate environmental issues while at the same time building for sustainable growth.

Our focus is, therefore, oriented towards four fundamental questions:

R1: How do local businesses in Cameroon understand the concept of CSR?

R2: In what ways is CSR expressed and implemented in practice by Cameroonian businesses?

R3: What impact do such practices have on the immediate environment?

R4: Why is there a need for local businesses to embrace CSR as a development tool for environmental protection and sustainable growth?

According to existing empirical research conducted ethical business practices and CSR go hand in hand. Growing demand has increased in CSR in the quest to synchronize traditional business goals and social accountabilities (Sotamenou et al., 2013; Omran, 2015). According to Goel \& Ramanathan (2014), ethical conduct supports the need for industries to incorporate social and environmental concerns as an important part of the business process. Furthermore, regions with high levels of poverty, environmental distress and socio-economic distress can incorporate CSR to help in mitigating societal problems (European Commission, 2011). As Sotamenou et al. (2013) indicate, for businesses to build sustainable growth and gain a competitive advantage they must understand the role they play as partners in community development. Therefore, further research is required to investigate the corporate conduct of local businesses in developing countries and their contribution to building sustainable growth. Moreover, existing research on CSR in emerging countries has mainly been centered on agendas developed in progressive countries and transposed to local multinationals (Demuijnck \& Ngnodjom, 2013). The reliance on hypotheses and theories from developed nations is a result of failure to take into consideration the context in which CSR policies are accepted and executed by local businesses (Jamali \& Karam, 2018). Consequently, there is a need for CSR research in developing economies to be centered on local businesses, as relating them to developed countries does not present the correct context of its applicability (Goel \& Ramanathan, 2014). Thus, this thesis aims at filling some of the missing gaps in the literature on CSR practices in emerging economies and Cameroon to be more specific.

\section{Review of Related Literature}

The available literature on corporate social responsibility is controversial and inconclusive as researchers are divergent on the constructs that inform the practice. In this section, a review of relevant literature to the study is conducted. The conceptual review assesses how the concept has been discussed by theorists and empirical researchers. The theoretical section takes a look at theories that inform the practice discussed in the context of the thesis. An empirical review of existing literature on CSR in Cameroon is also undertaken. A conclusive section summarizes the main issues from the literature review while identifying the gaps that need to be addressed to help mitigate some of the issues identified.

Conceptual Framework: The evolution of business activities beyond the scope of making a profit for shareholders has increasingly gained momentum over the years not only in business practice but in academics. Recent studies indicate that there is a significant recognition of the influence of business activities on society (Kolk, 2014), with ongoing debates on the role and obligations of business entities beyond those required by laws and regulations. With the recent business scandals such as those that contributed to the 2008 global recession, questions have been raised on how to regulate or deregulate businesses to protect stakeholders. To this end, there has been an increasing reliance on CSR to address some of the key issues of business ethics by strengthening the principles surrounding corporate governance and making companies more conscious of their responsibilities (Adda et al., 2016). The academic discussion on CSR has evolved in recent years from a minor field of study to a more complex and diverse framework. Most of the complexity emerges from the fact that the subject not only contains a lot of theories but also encompasses several often disputed approaches (Nikolova \& Arsić, 2017). From empirical literature, early academicians like Friedman (1970) argued that corporations were only socially responsible for creating profits and other social activities were incompatible with their role. 
Others like Bowen (1953) argued that CSR provided an alternative way of integrating societal concerns in business as opposed to the maximization of profit as the only operational concern. McGuire (1963) contended that there are other societal obligations placed on corporations other than those required by law and the need to make profits. Carroll (1979) expanded on this by indicating that firms can still make profits while obeying laws, being ethically responsible and being good corporate citizens. Recent approaches to CSR relates the concept to sustainable business development arguing that business activities should balance satisfying shareholders with undertaking social, environmental and economic responsibilities towards other stakeholders (Freeman, 1984). Over the years several frameworks have been developed to model the CSR concept as related to business practice. The earliest models such as that by the Committee for Economic Development (CED) (1971) based their work on the social contract theory which relied on the social interaction between businesses and the society to adopt the "three concentric circles" model. The model presented an inner circle synonymous with jobs, production and economic expansion. The intermediate circle was linked to issues like environmental conservation, hiring and employee relations management.

The outer circles included issues like poverty and urban development. Davis \& Blomstrom (1975) also came up with the "widening circle" approach similar to CED's approach. However, this earlier model was embedded with limitations given that the frameworks did not indicate how corporations were going to play their role. To overcome such limitations Carroll (1979) expanded on the earlier models and suggested a more comprehensive three-dimensional approach to corporate social responsibility to include what should be considered as corporate social responsibility, what issues corporations need to address and the organizational philosophy to be adopted. This approach is modelled as a pyramid of four key responsibilities and forms the basis of generally accepted CSR concepts. The fundamental economic responsibility of the business to produce goods and services for consumption while employing members of the community formed the base of the pyramid. According to Carroll (1979), this was the most critical dimension because its failure would undermine the success of the other components. The second component was the legal responsibility of corporations to conform to societal law and regulations.

Closely linked to the second component is the third stratum of the pyramid which underscores the ethical responsibilities compelling businesses to do what is right and not limit themselves only to those responsibilities required by law. The fourth component is philanthropic responsibility. Often referred to as the discretionary responsibility, it acknowledges the responsibility of corporations to promote goodwill and human welfare through philanthropy. This model conceptualization model contends that corporations have ethical and discretionary (philanthropic) as well as legal and economic obligations (Carroll 1979). The focus is that CSR strategies have to address a wide spectrum of societal obligations while meeting the most fundamental economic and legal functions of business entities. Other theorists like Sotamenou et al. (2013), identified dimensions of CSR to include philanthropy, economic, environmental, and social as well as stakeholder engagement. As Chakraborty (2015:37) indicates, "the term CSR is viewed as an umbrella concept and is still searching for a universally accepted definition, which covers all the concepts related to sustainable, responsible, and ethical business behavior".

CSR, Environmental Concerns and Sustainability: Existing empirical research on CSR for the vast majority tends to agree that there is international consensus to encourage the implementation of practices that address environmental and societal issues (Misztal \& Kaczmarek, 2014). Around the world, many corporations have come to realize the importance of environmental initiatives in business sustainability (Emezi, 2014). Environmental strategies like industrial ecology, energy efficiency, pollution prevention and waste management are emerging at the forefront of corporate priorities across the globe. To facilitate longterm growth, firms are also being encouraged to engage in environmental CSR initiatives. Following this framework, environmental laws and regulations are being developed into standards such as the ISO 140000 that companies need to adhere to mitigate environmental issues. However, there seem to be major challenges facing such initiatives. Issues such as poverty in some countries, income inequality, unsustainable consumption and climate change.

This has led to the debate on the contributions that CSR can make in improving the social, environmental and economic conditions of people within communities. Focusing on the Cameroonian context, empirical literature points to the fact that local businesses are yet to understand and fully embrace CSR concepts 
(Emezi, 2014; Ndzi, 2016). Furthermore, businesses are not interested in mitigating environmental issues related to their activities (Baxter, 2015; Ndzi, 2016). However, CSR in the country is evolving beyond the traditional practice of corporate philanthropy and starting to embrace community relations and sustainability (Emezi, 2014; Singh et al., 2017). Companies are now expected to go beyond legal and economic compliance and earn their 'license to operate by engaging in activities that are deemed to provide a beneficial impact (Adda et al., 2016; Baxter, 2015). Economic, environmental and social responsibilities related to business activities are issues that need to be resolved if emerging countries like Cameroon are to attain their objectives of building for sustainable growth (Emezi, 2014). The suggestion is that corporations in Cameroon need to integrate environmental and sustainability dimensions into their corporate strategies. This can be conceptualized through a model which advocates that firms create value through the different CSR dimensions.

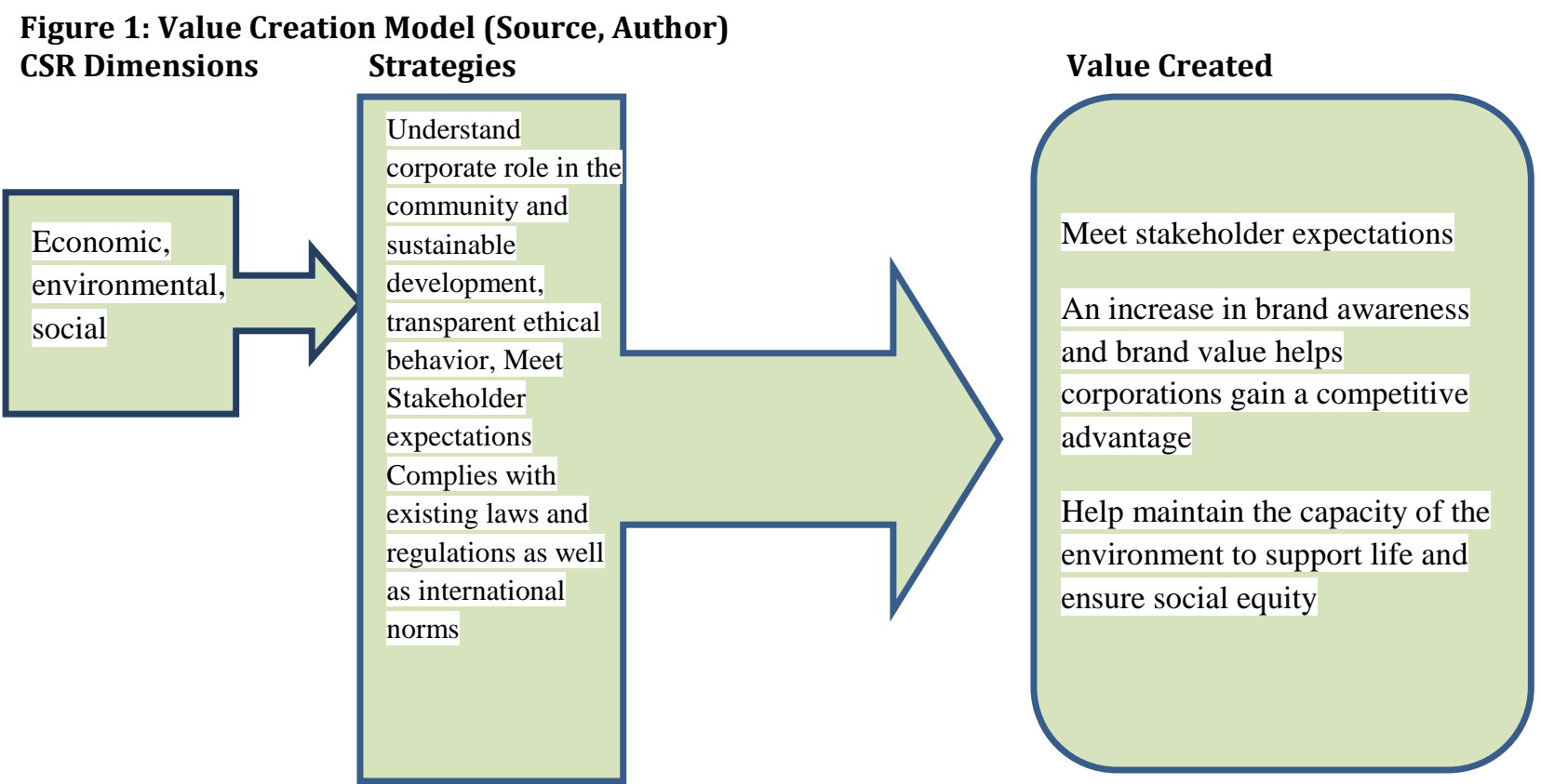

In the above approach, businesses simultaneously strive to satisfy environmental, economic and social concerns by creating value for all stakeholders. This gives corporations the capacity to engage with a multitude of stakeholders and address sustainable development issues (Emezi, 2014). Through the value creation model, corporate success and social welfare are interdependent and provide firms with opportunities for building social value propositions into corporate strategy, thereby building sustainability.

Theoretical Framework: Garriga \& Mele (2004:1) indicate that "the Corporate Social Responsibility field presents not only a landscape of theories but also a proliferation of approaches, which are controversial, complex and unclear". These theories are often related and focused on the four dimensions of environmental, social, economic, and philanthropy (Omran, 2015). Montiel \& Delgado-Ceballos, (2014) argue that the usefulness of each theory depends on the purpose and context. Fernando et al. (2014) indicate that three mainstream theories underline current CSR practices, namely institutional theory, stakeholder theory and legitimacy theory.

An Institutional Theory of CSR: The institutional theory views businesses as passive recipients of institutional pressure and argues that the engagements of firms are guided by their institutional context (Awolusi, 2021; Olayisade \& Awolusi, 2021). Brammer et al. (2012) concede that businesses often respond to the demands of corporate responsibility by broadening and reshaping most of the institutions that govern their economic, social and political systems. In this case, corporate behavior is influenced by institutional conditions such as laws and regulations both private and public, monitoring of corporate behavior by nongovernmental and other compliance institutions, associative behaviors and stakeholder dialogue (Campbell, 2007). This implies that corporations are concerned about social relationships, coexisting with other 
associations and institutional compliance. To be successful businesses must therefore adopt socially responsible behavior (Brammer et al., 2012).

Legitimacy Theory of CSR: The legitimacy theory draws its strength based on a social contract between organizations and communities in with they operate (Awolusi, Pelser, \& Adelekan, 2016; Omran, 2015). Legitimacy is defined by Dowling \& Pfeffer (1975:122) as "a condition or status which exists when an entity's value system is congruent with the value system of the larger social system of which the entity is a part. When a disparity, actual or potential, exists between the two value systems, there is a threat to the entity's legitimacy". As a result, companies adopting a legitimacy theory voluntarily act on the activities that they perceive are expected of them by the communities in which they operate (Deegan 2002). Under such circumstances, the organization's survival depends on its perception by the society, and if society is not satisfied with the organization's operations the contract is revoked. This forces businesses to be more responsive and responsible towards the communities in which they operate (Dowling \& Pfeffer, 1975).

The Stakeholder Theory: The stakeholder theory of CSR argues that to succeed, an ethical and pragmatic business must assume the vast interests of stakeholders and not limit itself to the interest of shareholders alone (Awosusi \& Awolusi, 2014; Freeman 1984, Garriga \& Mele, 2004). Proponents of this theory contend that businesses do not only have economic and legal responsibilities. They also have an ethical responsibility to all individuals and groups that contribute to the corporation's activities and growth. In this case, the business should also be responsible for those who could benefit from or are harmed by the company's activities. Another argument is that though maximizing the profit of shareholders is justified, social obligations are a strategic instrument for developing a competitive advantage (Emezi, 2014). Brammer et al. (2012) argue that the three theories have similarities, are complementary and can be linked to explain the CSR practice from a multi-theoretical approach. However, the author argues that stakeholder holder theory is more suitable for developing countries. Companies can target their CSR strategies towards those stakeholders by drawing inspiration from the ethical approach to mitigate some societal issues. In countries like Cameroon facing enormous environmental and social challenges, these companies can be enabled to function as agents of sustainable growth and development by being more responsible. Proponents of the ethical approach to CSR argue that a firm's interests and that of the society at large are closely linked together.

As such firms can mitigate some of the potential existential conflicts, by creating a "win-win" situation for both parties (Goel \& Ramanathan, 2014). By becoming more conscious of the effects of the activities within the community, firms can achieve better results by improving their social engagements. Emezi (2014) argues that businesses and communities prosper in conjunction when companies meet their obligations towards those affected by their activities. Singh et al. (2017) indicate that when developing business strategies corporations in developing countries must take into consideration their roles as participants in sustainable development and environmental protection. Ndzi (2016) suggests that corporations can achieve legitimacy by getting accreditations in environmental programs and implementing industry standards such as ISO 14000. Kolk (2014) suggests that despite the lack of conclusive evidence indicating that a firm's value is directly impacted by its engagement in the community, evidence points to the fact that by issuing CSR reports firms in developed countries gain goodwill with regulators and government agencies, setting them on the path to achieving sustainability. Emezi (2014) contends that corporations with good corporate policies on governance generally create more value for their shareholders and communities thereby ensuring sustainable growth and at the same time helping mitigate environmental concerns (Oladejo \& Awolusi, 2017).

Empirical Framework: There has been comprehensive research on CSR carried out in most developed nations such as the United States and other European nations. Nevertheless, studies in developing countries such as Cameroon are still at the conception stage due to the novelty of the idea (Ndzi, 2016). In a research study conducted by Ogini \& Omojowo (2016) on CSR in Cameroon, Corporate Social Responsibility policies and practices were classified into three main sets (social, economic and environmental). The study alleged that industries in the country are yet to recognize that adopting CSR policies will enable them to gain a competitive edge over their rivals. Adda et al. (2016) indicate that corporate social responsibility in Africa is driven by large multinationals. There is no input from locals as agendas from developed countries are simply transposed at local levels (Emezi, 2014). 
Empirical literature also indicates that the main vehicle for CSR in the country is philanthropy. A qualitative review conducted by Ndzi (2016:151) on the prospects of people living around ENEO, a power supply company in Cameroon, concluded that "businesses endorse the practice of CSR mainly through charitable projects in health, education and poverty eradication. Several businesses are engaged in development initiatives as an income-generating source and a platform for employment". Findings from the research concluded that CSR practices are inadequate and inept to have any substantial impact on the needs of the local population. A study by Akwaowo \& Swanson (2016) to assess the role of Foreign Direct Investors (FDI) in the eradication of poverty in Nigeria, Ghana and Cameroon through Corporate Social Responsibility argues that multinational companies still battle with difficulties in their quest to reduce poverty in host countries. This is due to the reliance on western business agendas which are majorly selfish (Emezi, 2014; Ndzi, 2016). The institutional context has been suggested in available literature as a major drawback to the evolution of CSR in the country (Ogini \& Omojowo, 2016; Emezi, 2014). A study done by Demuijnck \& Ngnodjom, (2013) using a hermeneutical approach based on interviews, aimed at gaining insight on how local small and medium-size businesses define and understood corporate responsibility concluded that there were no formalized CSR guidelines in place.

Furthermore, entrepreneurs are unable to act on the strategies due to a lack of awareness on the subject, matter fraud and inadequate legal frameworks and policies. The lack of regulation and public policy on corporate responsibility is one of the key challenges facing entrepreneurs in Cameroon (Ndzi, 2016; Demuijnck \& Ngnodjom, 2013; Sotamenou, 2014). According to Emezi (2014), it is the government's responsibility to improve the functionality of CSR by creating a conducive environment. However, most developing countries find it impracticable (Oginni \& Omojowo, 2016). To "understand the institutional setting and elements that are driving CSR practices in various African countries", Sotamenou et al. (2013) arrive at an institutional theory and conclude that in African countries CSR is "mainly compelled by the prerequisite to adapt to societal standards or copy the 'best practice' for validity reasons". Though the study is related to research conducted in Kenya, it can be effectively transcribed to other developing nations such as Cameroon. Researchers claim that governments in developing countries to induce foreign investment often refuse to enforce standards and regulations related to corporate responsibility (Emezi, 2014; Kolk, 2014). The disregard for policies related to environmental policies is an alternative dimension through which corporate responsibility in Cameroon is perceived. In our literature inquiries, inadequate studies related to the topic were established.

Sotamenou et al. (2013), embarked on qualitative research to gauge the environmental practices of managers in 277 small and medium-sized enterprises (SMEs) in Cameroon. The findings established that only 18\% of the managers had effected policies targeting environmental protection and only $12 \%$ of these companies had conducted environmental protection studies. A study by Baxter (2015) on CSR practices by Chinese industries in Cameroon established that these companies had not developed any environmental policies or these policies were fairly unidentified. Many industries in the country have total disregard for environmental protection policies. However, there was no suggestion on the bearing this had on the local environment. Studies indicate that socioeconomic disparities and the undesirable impact of business activities on the environs are prevalent in developing countries, obstructing the sustainable development of the host countries (Torrico et al., 2018). A variety of issues emerged from the literature review of CSR in Cameroon. First and foremost the CSR practice is virtually a new concept in the country. Hence, it is difficult for a business to comprehend it fully. Secondly, there is an absence of resilient government administration, which can be a great platform for companies to build on. Subsequently, companies keen to adopt favorable policies are sometimes held captive by social ills such as corruption, and lack of guidelines that can help them understand better the needs of local communities.

Furthermore, western multinational initiatives on CSR were the major concern of the majority of previous research, work. There was minimal input from local businesses. While some of the research was realistic, recommendations were made on theoretical constructs and hypotheses from a western view. Finally, there is scanty research linked to environmental conservation and pollution in developing countries and Cameroon in particular (Ndzi 2016; Demuijnck \& Ngnodjom, 2013). The related studies conducted on the topic failed to substantiate the impact on the local environment. Research on the intersection between CSR practices, sustainable growth and the environmental impact is not enough or absent. While conducting the empirical 
literature it is clear that there are existing gaps in the literature on the subject of corporate social responsibility in Cameroon. As Demuijnck \& Ngnodjom (2013) indicate, research on corporate social responsibility has largely been focused on multinationals with little or no input from local perspectives, making it difficult to understand CSR from a local context. Secondly, even when such literature exists, there has been a tendency to interpret findings without taking into consideration the context (Ndzi, 2016; Emezi, 2014) with assumptions mainly drawn from the context of developed countries. Additionally, the issue of environmental protection and sustainable development has not been sufficiently addressed by researchers (Sotamenou et al., 2013; Baxter 2015). This thesis is an effort to contribute to bridging the existing gaps between what has been done and what needs to be done to improve the understanding and practice of corporate social responsibility in Cameroon.

\section{Methodology}

The underlying assumption is that local corporations in Cameroon are not building for sustainable growth by neglecting environmental concerns in their day-to-day activities. Due to the nature of our research that seeks the opinion of the local business on CSR and environmental policies, the logical paradigm is focused on the interpretative model. The interpretive worldview holds that knowledge is considered valid when it is formulated through social paradigms that are conveyed by the research participants (Myers, 2008). It offers the investigator an epistemological method with a better space to recognize humans as communal actors and likewise helps us to understand the world to address matters of influence, particularly in circumstances where there are several socially created certainties (Creswell, 2012). The reality, in this case, is contextdriven since our purpose is to comprehend corporate responsibility in Cameroon through the outlook of the local businesses. Our investigation approach is thus inductive. Baxter (2015) opposes that the inductive approach is generally meant for qualitative research methods since clarifications can be found from the data and the theoretical framework used to support empirical findings. With this method, theory can be developed after an analysis of the data collected.

This method affords flexibility provided that it does not limit the researcher to pre-defined data (Zalaghi \& Khazaei, 2016). This suits our research objective which is to gain new insight into CSR concepts and practice in Cameroon. Kawulich (2012) contends that an interpretative paradigm typically utilizes a qualitative methodology. According to Creswell (2012) "a qualitative study is defined as an inquiry process of understanding a social or human problem, based on building a complex, holistic picture, formed with words, reporting detailed views of informants, and conducted in a natural setting". Bryman \& Bell (2011) oppose that, the goal of qualitative research is to discover patterns that emerge after close observation, careful documentation, and thoughtful analysis of the research data. This methodology is conducive for this thesis because it provides meanings and contexts to events, necessary to understand findings that can be used towards valuable theoretical interpretations (Baxter 2015:556). The researchers assume that this research method is better suited for contextual research analysis it can be used to illustrate the participant's views without changing the outcome (Baxter 2015). Additionally, empirical literature suggests that qualitative research can be used to address social issues and advocate for social changes (Creswell, 2012), thus aligning with a key objective of this study.

This study uses a multi-method design in which two or more types of qualitative data collection methods are used together to form essential components of the study. In such cases, multiple sources of evidence are required with data needing to converge. This allows for a more holistic approach and understanding of the phenomenon in question (Creswell, 2012). This is a method of research often used to study complex social phenomena recommended by scholars from several disciplines (Newman \& Benz, 1998; Creswell, 2012; Brewer \& Hunter, 1989). The choice of a multi-method design for this thesis was because it can provide an insightful view of the phenomenon which can help the researcher investigate the research questions. The researchers' choice of multiple methods was because they complement each other and also to overcome limitations of a single research method. Mingers (2001:241) argues that "different research methods (especially from different paradigms) focus on different aspects of reality and therefore a richer understanding of a research topic will be gained by combining several methods in a single piece of research or research program". For this study, two research methods interviews and questionnaires were chosen. 
Creswell (2012) indicates that primary data in the qualitative research process can be collected through questionnaires and/or interviews. The choice of questionnaires by the researcher is because this method of data collection is fast, cost-efficient, and data collected is more objective compared with other research methods (Ponto, 2015). It is an appropriate choice when the researcher's aim to explore often contested topics. Alshenqeeti (2014:36) argues that "as a data collection method researchers can use interviews in cases where the issues concerned are very specific, leading to more focused and constructive suggestions. He further contends that "researchers often find interviews useful to provide detailed descriptions of individuals and events in their natural settings". Creswell (2012) also argues that interviews are conducive to gathering detailed data from a few participants. The target populations for this research were local industries located within the Bonaberi industrial zone in Douala the economic capital of Cameroon. The suitability of this zone was due to the concentration of industries within the locality that is majorly associated with industrial waste and environmental degradation (Tematio, 2012). However, this population can be assumed as a representation of most businesses in Cameroon.

According to Wilfred et al. (2018), environmental health remains the main concern in Cameroon as dumping of industrial waste and chemical leaks into open fields are a common occurrence. Twenty (20) local businesses participated in the process based on selective sampling. Based on intent, purposive sampling was conducted and as a result, the researcher selected businesses whose activities were confined within the borders of the country. It should be noted that in line with the authors' aim to examine the concept through the lens of local businesses, no multinational was selected for the study since empirical literature indicates most CSR initiatives in Africa are by multinationals (Emezi, 2014; Baxter, 2015; Ndzi, 2016). Most of the respondents solicited for the process were senior executives who by the positions could have valuable knowledge about the CSR initiatives of their companies. This method of sampling is particularly useful in qualitative research because it is time and cost-effective and ideal for exploratory research design (Taherdoost, 2016). Secondly, the choice of questionnaires was to make sure that everyone in the sample answered the same questions, making it a very reliable method of research. However in addition to volunteer bias, the findings though valid might not necessarily be representative.

As earlier indicated, two data collection methods are used in this study. For the first instrument, a set of structured questions were mailed to participants with instructions to answer the questions and return the questionnaire. The structured questions were designed based on the research objectives, with questions regarding their CSR initiatives and whether these initiatives were directed towards environmental concerns and sustainable growth. Additionally, follow-up unstructured phone interviews were conducted to clarify unclear answers provided on the questionnaires (Awolusi \& Atiku, 2019; Singleton \& Straits, 2009). Baxter (2015) indicates that when conducting research it is important to address issues of ethics and privacy. To address these, the researcher ensured steps were taken to maintain participants' rights and ensure that their privacy was not intruded upon by providing them with a form stipulating the purpose of the study and how confidentially was guaranteed. The researcher also made sure that the informed consent of participants was received in writing. The research instruments were designed following the problem identification and establishing of the research objectives. The Peterson (2000) model was used where existing literature was reviewed and research questions developed, a method known as "classifications of questions".

The questionnaires were self-completed (See Appendix A). The questionnaires were sent to the participant by mail since it was more convenient due to the various engagements of participants. This was preceded by an unstructured phone interview to allow the researcher to develop a keen understanding of the phenomenon and for the respondents to provide more explanations if the answers they provided on the questionnaire were vague (Baxter, 2015). The data collected was analyzed using content analysis. Griffiths (2016:30) argues that "content analysis of replies to closed questions in questionnaires can be undertaken to understand remarks that may explain the responses". Bengtsson (2016:8) indicates that "the purpose of content analysis is to organize and elicit meaning from the data collected and to draw realistic conclusions from it". According to Sandelowski \& Barroso (2003), when conducting qualitative research using an inductive approach in phenomenology, thematic content analysis is suitable for research where a low level of interpretation will be employed. In this work, open coding was used to collate codes into potential themes, themes were then reviewed and a thematic map was generated. 
This involves discovering themes in the interview transcripts and attempting to verify, confirm and qualify them by searching through the data and repeating the process to identify further themes and categories. A review was done to check if the themes work about the coded extracts and the entire data set. Clear definitions and names for each theme were then generated. An analysis was then done for selected extracts, relating the analysis to the research question and literature. A report of the analysis was then produced. This was done using Microsoft Word and Microsoft Excel software. This method was chosen as it is extremely lowcost and suitable for the project because of the small quantity of data used. However, it is probably not suitable for bigger or longer-term projects, where codes continually evolve and you can't easily rename a code and have the change reflected. The researcher's choice of this method is because it is inductive and can be used to make faithful inferences. Griffiths (2016) argues that inductive content analysis can be used where there are limited previous theories or research findings. Literature indicates that for the results to be reliable, the study should be replicated.

In the case of the present research, this is problematic as the environmental setting and social context in which the study was conducted are constantly mutating (Bryman \& Bell, 2011). Another drawback is that given the interpretative research paradigm, the results are based on the interpretation of the researcher rather than facts. That being said, efforts were made by the researcher to limit bias and anchor the work on existing theories and empirical literature to make it reliable (Cohen et al., 2007). Furthermore, when conducting research we found that this research work aligned with other research conducted on CSR in Cameroon by Demuijnck \& Ngnodjom (2013) and Sotemenou (2013) making it reliable. Evaluating the validity of research is to ascertain its trustworthiness and credibility (Bryman \& Bell, 2011). Literature indicates that a research study should be valid when credible scientific publications and literature sources can be used to ascertain the research work. Given the nature of this research work which is based on interpretation rather than facts, it becomes relatively difficult to meet the stated benchmarks. That being said, efforts have been made in the study to relate and support the work with credible existing literature. Furthermore our research approach and choice of methods is to enhance the credibility of the study (Yin, 2014).

\section{Results and Discussion of Findings}

Demographic Data Analysis: For the research, work themes were chosen for our research objectives. The summary table below identifies the chosen themes captured and the number of participants who indicated that they had addressed the issue. All names have been changed to protect participant information and confidentiality.

Table 1

\begin{tabular}{|c|c|c|}
\hline Themes & Meaning & Frequency \\
\hline Knowledge of CSR & Know the concept or practice & 18 \\
\hline Promotion of CSR & $\begin{array}{l}\text { Have policies or teams in place to promote the } \\
\text { CSR practice. }\end{array}$ & 8 \\
\hline Philanthropy & The practice of CSR is limited to philanthropy. & 5 \\
\hline Stakeholder engagement & $\begin{array}{l}\text { Engage in dialogue with all members of society } \\
\text { and reflect outside opinions in business activities } \\
\text { while continuously examining their actions to } \\
\text { ensure that they meet society's demands and } \\
\text { expectations. }\end{array}$ & 4 \\
\hline Address environmental issues & $\begin{array}{l}\text { Provide environmentally conscious products and } \\
\text { services. }\end{array}$ & 4 \\
\hline Sustainability & Manage resource usage and supply over time & 4 \\
\hline Government support & $\begin{array}{l}\text { Government initiatives to encourage or constraint } \\
\text { businesses to meet community needs and } \\
\text { environmental protection }\end{array}$ & 3 \\
\hline Readiness to embrace CSR & Willingness to embrace CSR & 10 \\
\hline
\end{tabular}


Results: Working with the interviews of some business representatives about CSR in Cameroon, it was important to look at the data and identify specific themes that informed the research agenda and examine the response from participants. After categorizing and processing the matrices, the following information was captured for each theme.

Knowledge of CSR: This theme captured participants' knowledge of the CSR concept. It was clear that most respondents had some knowledge of the concept. $90 \%$ of respondents 18 out of 20 acknowledge that they had some knowledge about the topic. However, a majority indicated that it was relatively new for them. As respondent A16 states: "This is a new concept which was presented at a seminar I attended a few months ago". The respondents did not however indicate if they are willing to further their understanding of the topic.

Promotion of CSR: With regards to the promotion of CSR, less the $50 \%$ of the respondents indicated they had policies in place to promote CSR. The practice is still gaining momentum in the country. Participant A1 contends "My board has started pushing for us to adopt a more socially conscious business approach", while participant A16 indicates "We do have CSR initiatives as part of our corporate strategy. However, there is limited funding for such initiatives".

Philanthropy: On the themes theme of philanthropy, most businesses leaders associated CSR with philanthropy. Few companies understood CSR as a means of satisfying the needs of all stakeholders. There were a limited number of companies $20 \%$ that indicated they had that incorporated all stakeholders' needs into their CSR policies. However most attributed their participation to mainly greenwashing activities as a means to acquire legitimacy in the public. CSR initiatives in this case are not designed to produce profits or directly improve business performance but corporate image. For example participant, A12 indicated "we often donate money or equipment to schools".

Stakeholder Engagement: On the theme of stakeholder engagement, some participants (20\%) indicated that they "do engage with stakeholders to find out what social actions matter to them and see what activities can fit in" (A12)".

Environmental Protection and Sustainability: Sustainability was another theme addressed in the analysis. Only $20 \%$ of participants had policies directed towards the sustainable management of resources. Respondent A7 for example argued that "given that the more pressure to develop environmentally-conscious programs. Most of our activities not geared towards providing environmentally conscious products and services" A17 indicated that "We try to minimize the environmental impact in our production activities".

Government Support: A majority indicated the lack of support from the government as one of the issues hampering the promotion of CRS initiatives. Some participants indicated that "the government sometimes intervenes to make environmental protection standards where followed (A6)". However, "companies did not do no more than address issues not enforced by regulations" (A13).

Readiness to Embrace CSR: Despite advances made in the promotion of CSR initiatives in Cameroon, many companies were not ready to embrace CSR without some form of encouragement or regulations requiring them to do so. Companies seem less interested in totally integrating CSR within their business strategies and goals. This was evident from the responses of participants.

Discussion of Findings: In this study as with similar empirical literature on CSR in Cameroon (Ndzi, 2016; Baxter, 2015; Sotamenou, 2014) the most vital finding is poor scores on CSR awareness. It has emerged that the concept is still gaining ground in the country, with state and private entities not doing enough towards engaging companies on CSR initiatives. A significant majority of corporate initiatives lack effective CSR policies as well as teams to deal with social responsibility matters. Moreover, the main CSR method through philanthropy reinforces the idea that most companies are mainly fascinated by making substantial profits at the expense of social responsiveness (Ndzi, 2016). In practice, most of what is labelled as "CSR" is mostly driven by the concerns of legitimacy (Demuijnck \& Ngnodjom, 2013; Sotamenou, 2014). This has resulted in CSR practices that are largely derived from multinationals and transposed to local businesses (Baxter, 2015). However, there are increasing concerns that the "one size fits all" approach to CSR is ineffective. 
In mitigating social challenges and building for sustainable growth (Emezi, 2014). The challenge then for local authorities and businesses is to shape CSR agenda that is responsive to the local, context. Despite advances made in the development of CSR initiatives in Cameroon, we find that there is a need to address environmental issues as there is limited to no interest in environmental protection and community engagement initiatives (Ndzi, 2016; Emezi 2014). Communities have aped this trend by engaging in activities that undermine environmental sustainability (Abia et al., 2018). Likewise, it is worth noting that the government has not empowered local authorities to undertake initiatives that touch on environmental matters (Baxter, 2015). Laws and policies put forth by the government have not been effective. Besides, the lack of government backing and willpower to promote viable development dents the quest for companies to establish appropriate CSR policies. This inefficiency is a reflection of poor leadership that threatens the identification of priority areas that promote sustainable development. Environmental protection has been overlooked by the Cameroonian government with no proper policies and legislation to ensure sustainability (Ndzi, 2016). The government agencies responsible for checking environmental matters lack resources to create awareness.

The overall lack of government support has affected the performance and capability of companies in generating, consciousness for sustainable development issues (Sotamenou et al., 2013). It can be concluded that the environmental impact of CSR in the Cameroonian context, as evident in this research work, is rather negative. The primary reason as identified by the author and supported by existing literature seems to be the inappropriate approach towards the practical applicability of CSR in the country. There is a gap in the structural approach towards the implementation of the CSR agenda by businesses within the country, mainly due to a lack of understanding of the concept and irresponsible inactiveness on the part of the government in framing its policies and regulations. This study supports the contentions of Ndzi (2016), Emezi (2014) and others that current CSR practices in developing countries do not particularly address issues that are relevant to the local context. There is a need to understand the potential and limitations of current CSR practices with a more rounded consideration of the context-specific issues facing developing countries. This does not only entail that imported CSR theories and concepts be questioned.

But also the need to find out if CSR in its current form is an appropriate medium through which social change can be propagated in developing countries (Jamali \& Karam, 2018). The author encountered a few instances where respondents were eager to embrace CSR without some sort of legislation requiring them to do so. This illustrates the fact that businesses do not yet understand their role in building sustainable communities, but also do not see the opportunities that CSR presents for them to build a competitive advantage over their rivals. However, other researchers like Kolk (2014) argue that there is no conclusive evidence indicating that a firm's value is directly linked to community investments. While this might hold, this does not negate the fact that firms can gain goodwill from regulators and government agencies by submitting CSR reports. Much of empirical literature seems to suggest that firms that have invested in social programs improve their financial and operational performance leading to sustainability and growth (Emezi, 2014; Adda et al., 2016). Perhaps the most important lesson to be learned from this study is that in failing to embrace CSR as a vehicle for social change local businesses in Cameroon are not only failing to address the consequences of their actions (Ndzi, 2016) but at the same time fail to build for sustainable growth (Emezi, 2014).

\section{Summary, Conclusion and Policy Recommendations}

Summary: The theory of corporate social responsibility (CSR) assesses the role of business in the community to capitalize on the constructive societal outcomes of entrepreneurial activities. The practice aims to promote business engagement and improve efforts to meet the needs of all stakeholders. In other words, it helps corporations become socially accountable to the stakeholders and the general public. Through the adoption of Corporate Social Responsibility, industries can gauge themselves in terms of the influence they have in all facets of society. Despite the efforts to popularize this model, there are many gaps both in research and in implementation in Cameroon. The problem is that Cameroon, like other developing nations, has not been able to enforce legislation that guards its local communities against exploitation and business malpractice (Akwaowo \& Swanson, 2016). Corporate Social Responsibility is perceived as a humanitarian gesture rather than a planned model to mitigate developmental issues. Additionally, weak government institutions, gaps in public governance, inadequate CSR approaches have been major obstacles in the implementation of CSR. 
This has left local communities battling with issues of environmental degradation and corporate irresponsibility (Oginni \& Omojowo, 2016). The perception of the local communities as partners in community development, the implementation of CSR policies, and the impact of the policies on the environment are stated problems that the thesis sought to answer. Additionally, existing literature seems to suggest that agendas mostly drive the discussion and practice of CSR in developing countries from the developed world with little or no contextual dependence on the specific contexts of developing countries. Hence, there is a need to understand the practices and consequences of CSR that are relevant to developing countries. This is what this thesis seeks to address. Anchored on (Freeman, 1984) stakeholder theory which believes that business strategies should be harmonized for all stakeholders, the author aimed to understand the CSR concept as understood and practiced in Cameroon with its resulting impact on the environment. The research examined the interpretation of the local business community on their understanding of CSR. The perception of local businesses on CSR in developing the communities, policies that the locals have developed towards CSR.

The need to embrace CSR as a development tool formed the objectives of the study (Ndzi, 2016). The questions that guided the research were centered on the comprehension of the concept of CSR by local businesses, its implementation, the impact of its practices on the immediate environment, and its importance in environmental sustainability. The missing gaps in literature among developing economies were an essential reason for conducting this research. The divergent nature of the CSR model has been the reason for controversy in its study. The available literature is inconclusive with the emergence of a variety of theoretical views. In Cameroon, there are many existing gaps in the literature on CSR. As Demuijnck \& Ngnodjom (2013) specify, research on corporate social responsibility has primarily been concentrated on multinationals with little input from the local outlook, making it challenging to understand CSR from a Cameroonian point of view. Even existing literature consists of a biased perception with inferences made to developed countries and the local context overlooked. Environmental sustainability is also a less researched area concerning CSR. These are the significant gaps that the thesis wanted to address. Using a multi-method data collection tool, content analysis was used in this study to examine the CSR practices of 20 local businesses in Cameroon.

The investigative approach was inductive since it is a qualitative study. Structured questionnaires and followup interviews were the research methods used since it was a convenient way to collect primary data. Ethical issues were adhered to during data collection. Validity and reliability were addressed by ensuring broad comparison with related research. The analysis process was thematic content analysis in which the questionnaires were transcribed. Development of categories was used to address the research questions from the raw data and a framework developed to capture key themes. From the findings, it was gathered that CSR was relatively a new concept and most respondents associated it mainly with philanthropy. Also, few companies stated that they were environmentally conservation conscious. It was evident that corporate responsiveness and environmental safety were not popular ideas among the respondents. A significant majority of corporate initiatives lack effective CSR policies as well as teams to deal with social responsibility issues. Most companies aim at making profits with no regard for social responsiveness. SMEs were steered towards personal growth with limited interests in sustainable development. Lack of government support on environmental matters has contributed to minimal community participation.

Conclusion: Following a review of the work presented above, we can arrive at certain conclusions relating to the practice of CSR in Cameroon. In terms of the CSR practice, there is some momentum towards responsible business practice as evidenced by a growing number of researches on the topic. There is also more pressure being put on businesses to become more responsible and mitigate the negative effects of their activities. However, as evident in this research work and supported by existing literature, the impact of CSR initiatives in the country is rather negative. An inappropriate approach to CSR through philanthropy, weak government institutions, gaps in public governance and a lack of understanding of the concept have been major obstacles in the implementation of CSR.

CSR as practice and defined primarily from the agendas of developed countries has limited benefits and is an obstacle to sustainable growth. It will be more advantageous for focal authorities and businesses to set a CSR agenda for themselves based on local priorities and context (Emezi, 2014). Local businesses may need assistance in understanding CSR concepts to be able to respond effectively to community demands. More 
importantly, there is a need to assess the undesirable side effects of CSR practices on the environment. CSR initiatives should be seen to contribute to an enabling environment to sustain business initiatives not limit them. This study contends that if the country intends to fight environmental issues and build for sustainable growth then it must encourage commitment to CSR in all its aspects.

Recommendations and Policy Implications: Based on the study findings, several recommendations can be developed to improve the awareness and practice of CSR by local businesses in Cameroon. The first recommendation involves public-sector involvement in CSR goals. As noted earlier one of the major issues plaguing the CSR practice in Cameroon is weak government institutions and public governance. To resolve this issue, the Cameroonian government needs to empower its regulatory bodies with the ability to enforce existing laws and regulations related to CSR. The Cameroon government should also utilize the CSR concept to advocate socially responsible modes of business practices by local enterprises. The government should liaise with international donor organizations to support business development operations designed to promote environmental sustainability. Secondly, it has been observed from the study that CSR awareness in the local business environment is minimal. As such, there is a need to promote the awareness and practice of CSR for local businesses in the country. Some of the approaches that can be used to improve CSR awareness include; developing peer training on CSR during business events, allowing team members and staff to participate in volunteer programs within the local community, sharing success stories that can help business and the community understand the interest and importance of CSR issues. Through the promoting of CSR through legislation and by encouraging stakeholder awareness, rising companies and the society, in general, can help mitigate some of the social challenges within local communities.

To resolve the issue of over-reliance on corporate philanthropy, local businesses ought to improve their, ethical behaviors in their daily operations. To achieve lasting social change, most companies in the country need to broaden their approach to CSR. For example, businesses can integrate ethical sourcing practices to improve conditions for vulnerable communities. Businesses also need to be educated on the benefits of CSR. Studies indicate that improving responsible behaviors will always benefit the responsible firm (Singh et al., 2017). As such, businesses can thrive while also playing a major role in solving global issues. The results also reveal minimal societal involvement in CSR initiatives. Issues of community engagement can be resolved by developing models that include dedicated resourcing for citizenship engagement. In this regard, it should be acknowledged that the public is entitled to participate in CSR activities. The government should help by legalizing public involvement in all customer-facing units and activities. Communities should participate as consulting partners and should be informed of their entitlements to obtain favorable outcomes. These policies will help obtain benefits for society at the local level by demanding better-negotiated contracts between companies and communities. It has also emerged that community development cannot materialize without environmental protection, as environmental negligence and poor management of natural resources spill to the community level. The damages to the environment are immense as seen in the dwindling natural resources. The availability of water has significantly reduced over time due to inappropriate activities.

There are also concerns that the changing climatic conditions in the country are a reflection of poor environmental protection policies. If not controlled, local communities will continue experiencing challenges in meeting some of their needs due to inadequate ecological protection (Sotamenou, 2014). In this regard, CSR policies should be codified to encourage and compel businesses on the need for environmental protection. Companies should also be required to produce annual sustainability reports. This will be key in addressing some of the above-mentioned issues. The present study has made a notable contribution to knowledge. The study aims to determine the impact of CSR activities on environmental and sustainable growth. In particular, it sought to identify ways in which local businesses in Cameroon understand CSR, the role in developing communities, policies that they have adopted and the ways they have affected the environment, as well as the reasons for embracing CSR. Thus, this study has contributed to the literature on CSR in developing countries. It has been established that many businesses do not understand CSR practices and have to create dedicated teams to the practice (Baxter, 2015). A poor community engagement and lack of prioritization of environmental protection policies show that CSR in Cameroun is not taken seriously. In this way, the study has helped to fill the gap in information about corporate social responsibility in developing countries. Most people believe that companies that participate in philanthropic activities are socially responsible. 
However, this study has uncovered the fact a majority of the local businesses in Cameroun merely green wash, their CSR practice, but in reality, they have done little to improve the communities in which they operate. The study has exposed not only the inability of local companies from adopting CSR, but also the laxity of the government in enforcing the relevant laws and legislation. Besides expanding knowledge about the level of CSR awareness and practice in the developing country, the study has also highlighted the strategies that local businesses and the authorities can embrace to improve CSR performance (Demuijnck \& Ngnodjom, 2013). Governments in developing countries should ensure that they enforce all the relevant laws related to environmental protection and corporate social responsibility. The study has also recommended the need for collaboration and concerted efforts among different stakeholders, including the government, community, and local businesses to enhance CSR (Freeman, 1984). Most of the previous studies have focused on multinational organizations and their impact on sustainable development and the environment in developing countries. As a result, there are limited studies on local businesses. Thus, the present study fills this gap in knowledge by providing deep insights from local companies. However, the use of selective sampling in the thesis focusing on a few businesses makes it difficult to generalize. Due to the researcher's bias with regards to qualitative data interpretation the accuracy of the findings can be highly affected (Griffiths, 2016).

The qualitative approach enables the drawing of different conclusions from the research following the interpretation and perspective of the researcher (Griffiths, 2016). Thus the outcomes are more about opinion than facts. Another constraint with interviews is that the process cannot be replicated (Cho \& Trent, 2006). Despite its limitations, the method is still practical in conducting qualitative research. Future research should focus on multiple businesses to obtain more accurate and generalizable results on corporate social responsibility. It should examine different types of companies in the private sector as well as public companies to ascertain the degree of understanding of CSR. Secondly, future research should consider CSR from the customer's perspective. More often than not, companies engage in green washing activities and may not give an accurate picture of what they do. Thus, engaging the end-users would help in determining whether businesses embrace CSR. For instance, future studies should consider the views and opinions of the locals on the impact of a company in their community. Although the present research has uncovered the level of awareness and practice of CSR, there is a need to commission a study on the degree of green washing among businesses in the country. Beyond examining the level of CSR awareness among companies, future research should focus on the general and internal contextual factors that affect the adoption and practice of CSR in developing countries (Baxter, 2015). They should consider factors such as economic, political, cultural contexts, stakeholders and media pressure among others. By so doing, researchers will uncover the significant determinants of CSR practice and reporting.

Future studies should compare ways in which stakeholders perceive CSR reporting and compare with the perception of reporting by employees and managers. It will help identify, if any, discrepancies in what businesses profess and what they do. Moreover, future studies should consider a longitudinal design to gather more valid responses or opinions about CSR. Considering that participants' view changes with time due to the influence of different factors, researchers must capture the difference in the views to obtain a more accurate picture of the level of awareness of CSR among businesses. A longitudinal study that covers a broader time frame would help provide more effective results on the CSR position in developing nations (Bell \& Bryman, 2011). A comparative case study of multinational corporations and local businesses operating in the region of study can be pursued to determine the strategies adopted as well as identify the success stories to improve CSR practice and reporting. Considering that the current research focuses on understanding the level of practice of CSR in Cameroon, it is recommended that future research should consider examining its impact on business performance in the country. Perhaps, this would help create a business case for the adoption of CSR in organizations. Since the current research gives empirical insights into the corporate social responsibility practice of businesses in countries like Kenya, it would be interesting for researchers to seek similar ideas in other developing countries not only in Africa but also in Asia and Latin America. 


\section{References}

Abia, W. A., Mbako, J. D. \& Njoya, E. M. (2018). Environmental health concerns in Cameroon. Research Gate. DOI: 10.1016/B978-0-12-409548-9.10628-1.

Adda, G., Azigwe, J. B. \& Awuni, A. A. (2016). Business ethics and corporate social responsibility for business success and growth, European Journal of Business and Innovation Research, 4(6), 26-42.

Alshenqeeti, H. (2014). Interviewing as a Data Collection Method: A Critical Review, English Linguistics Research, 3(1), 234-245.

Akwaowo, E. \& Swanson, A. (2016). Foreign Direct Investment, Corporate Social Responsibility, and poverty alleviation: Evidence from African countries. Review of Business and Finance Studies, 7(2), 21-33.

Arsic, A., Stankovic, A. \& Mihajlovic, I. N. (2017). The most important dimensions of corporate social responsibility, International May Conference on Strategic Management, Bor, Serbia.

Awolusi, O. D. (2021). Economic Growth and Socioeconomic Sustainability in BRICS Countries: A Vector Error Correction Modeling Approach, Journal of Economics and Behavioral Studies, 13(3), 1-23.

Awolusi, O. D. \& Atiku, O. S. (2019). Business Process Re-Engineering and Profitability in the Nigerian Oil and Gas Industry: The Mediating Influence of Operational Performance, Information Management and Business Review, 11(3), 13-26.

Awolusi, O. D., Pelser, T. G. \& Adelekan, A. S. (2016). Determinants of Foreign Direct Investment: New Granger Causality Evidence from Asian and African Economies, Journal of Economics and Behavioral Studies, 8(1), 104-119.

Awosusi, O. O. \& Awolusi, O. D. (2014). Technology Transfer, Foreign Direct Investment and Economic Growth in Nigeria, Africa Development, 39(2),1-20.

Baxter, J. (2015). Cameroon: A case study of Chinese Corporate Social Responsibility, Forest News.

Bell, E. \& Bryman, A. (2011). Business research methods. New York: Oxford University.

Bengtsson, M. (2016). How to plan and perform a qualitative study using content analysis. Nursing Plus Open, 2(1), 8-14.

Brewer, J. \& Hunter, A. (1989). Multimethod research. A synthesis of styles. Newbury Park, CA: SAGE Publications.

Bowen, H. R. (1953). Social Responsibility of the Businessman. New York: Harper \& Row.

Brammer, S., Jackson, G. \& Matten, D. (2012). Corporate Social Responsibility and Institutional Theory: New Perspectives on Private Governance, Socio-Economic Review, 10(22), 3-28.

Campbell, J. (2007). Why Would Corporations Behave in Socially Responsible Ways? An Institutional Theory of Corporate Social Responsibility. The Academy of Management Review, 32(3), 946-967.

Carroll, A. (1979). A Three-dimensional model Conceptual Model of Corporate Social Performance. Academy of Management Review, 4(4), 497-505.

Chakraborty, U. K. (2015). Developments in the Concept of Corporate Social Responsibility (CSR), the Researchers, 1(1), 23-45.

Cohen, L., Manion, L. \& Morison, K. (2007). Research Methods in Education. (6th ed.). London: Routledge.

Creswell, J. W. (2012). Research design. Qualitative, quantitative, and mixed methods approach. Thousand Oaks, CA: SAGE Publications.

Davis \& Blomstrom. (1975). Business and Society; Environment and responsibility (3 ${ }^{\text {rd }}$ Edition), New York McGraw-Hill.

Deegan, C. (2002). The Legitimizing Effect of Social and Environmental Disclosures- A Theoretical Foundation, Accounting, Auditing and Accountability Journal, 15(3), 282-311.

Demuijnck, G. \& Ngnodjom, H. (2013). Responsibility and Informal CSR in Formal Cameroonian SMEs. Journal of Business Ethics, 112(4), 653-665.

Dowling, J. \& Pfeffer, J. (1975). Organizational legitimacy: Social values and organizational behavior, Pacific Sociological Review, 18(1), 122-36.

Emezi, C. N. (2014). Corporate Social Responsibility: A strategic tool to achieve corporate objective, Responsibility \& Sustainability, 2(3), 43-56.

Fernando, S. \& Lawrence, S. (2014). A theoretical framework for CSR practices: integrating legitimacy theory, stakeholder theory and institutional theory, Journal of theoretical accounting research, 10(1), 149178.

Flammer, C. (2013). Corporate social responsibility and shareholder reaction: The environmental awareness of investors. Academy of Management Journal, 56(1), 758-781. 
Fontaine, M. (2013). Corporate Social Responsibility and Sustainability: The New Bottom Line? International Journal of Business and Social Science, 4(4), 110-119.

Freeman, R. E. (1984). Strategic management: A stakeholder approach. Boston, MA: Pitman.

Friedman, M. (1970, September 13). The social responsibility of a business is to increase its profits. New York Times Magazine, 9(1), 32-33.

Jamali, D. \& Karam, C. M. (2018). CSR in Developed Versus Developing Countries: A Comparative Glimpse. Handbook of Research on Corporate Social Responsibility, Edward Elgar Publishing.

Kolk, A. (2014). The social responsibility of international business: From ethics and the environment to CSR and sustainable development. Journal of World Business, 51(1), 23-34.

Kawulich, B. (2012). Doing Social Research: A global context, Publisher: McGraw Hill

Garriga, E. \& Melé, D. (2004). Corporate Social Responsibility Theories: Mapping the Territory. Journal of Business Ethics, 53(1/2), 51-71.

Goel, M. \& Ramanathan, P. E. (2014). Business Ethics and Corporate Social Responsibility; is there a dividing line? Procedia Economics and Finance, 11(1), 49-59.

Griffiths, H. (2016). Application of summative content analysis to a postal questionnaire. Nursing Research, 23(3), 30-36.

Newman, I. \& Benz, C. R. (1998). Qualitative-quantitative research methodology; exploring the interactive continuum. Carbondale and Edwardsville, IL: Southern Illinois University Press.

Ndzi. (2016). Corporate Social Responsibility in Cameroon: The Hydro Electricity Sector, African Journal of Business Management, 10(7), 151-161.

Nikolova \& Arsić. (2017). The stakeholder approach in corporate social responsibility, Engineering Management, 3(1), 24-35.

McGuire, J. W. (1963). Business and Society. N. J, USA: McGraw-Hill.

Mingers, J. (2001). Combining is research methods: Towards a pluralist methodology. Information Systems Research, 12(3), 240-259.

Misztal, A. \& Kaczmarek, M. J. (2014). Environmental issues of the corporate social responsibility, Management, 18(1), 58-70.

Montiel, I. \& Delgado-Ceballos, J. (2014). Defining and measuring corporate sustainability: Are we there yet? Organization and Environment, 1-27.

Myers, M. D. (2008). Qualitative Research in Business \& Management" SAGE Publications.

Odunlami, S. A., Awosusi, 0. 0. \& AwolusiI, O. D. (2017). The Influence of Leadership Styles on Employees' Performance: A study of Selected Private Universities in Ogun State, Nigeria, Global Journal of Commerce and Management Perspective, 6(2), 5-13.

Oginni, O. S. \& Omojowo A. D. (2016). Sustainable Development and Corporate Social Responsibility in SubSaharan Africa: Evidence from Industries in Cameroon. Economies, 4(10), 1-15.

Oladejo, M. J. \& Awolusi, O. D. (2017). Effect of Work-Family Role Conflicts on Employees' Commitment and Organisational Performance: A study of AKLAD Interlink concept, Nigeria, Global Journal of Commerce and Management Perspective, 7(2), 81-96.

Olayisade, A. \& Awolusi, O. D. (2021). The Effect of Leadership Styles on Employee's Productivity in the Nigerian Oil and Gas Industry, Information Management and Business Review, 13(1), 47-64.

Omran, M. A. (2015). Theoretical perspectives on corporate social responsibility disclosure: A critical review, International Journal of Accounting and Financial Reporting, 5(2), 38-55.

Prates. (2015). Corporate Social Responsibility: A Case Study in Subsidiaries from Brazil and China, Journal of Technology Management \& Innovation, 10(3), 131-142.

Ponto, J. (2015). Understanding and Evaluating Survey Research, Journal of the advanced practitioner in oncology, 6(2), 168-171.

Sandelowski, M. \& Barroso, J. (2003). Writing the proposal for a qualitative research methodology project. Qual. Health Res, 13(6), 781-820.

Singleton, R. A. \& Straits B. C. (2009). Approaches to social research. New York: Oxford University Press.

Singh, P., Sethuraman, K. \& Lam, J. (2017). Impact of Corporate Social Responsibility Dimensions on Firm Value: Some Evidence from Hong Kong and China, Sustainability, 9(1), 1502-1532.

Sotamenou. (2013). Corporate Social Responsibility (CSR) among SMEs in Cameroon: Entrenching Environmental Conservation within Small Business.

Sotamenou, J. (2014). Corporate social responsibility among small and medium-sized enterprises in Cameroon, Journal of Entrepreneurship and Innovation Management, 3(2), 1-19. 
Peterson Robert, A. (2000). Constructing Effective Questionnaires, Thousand Oaks, Calif: Sage Publications.

Tematio. (2012). Pollution des eaux superficielles ET des nappes en milieu urbain: cas de la zone industrielle de Douala-Bassa (Cameroun).

Taherdoost, H. (2016). Sampling Methods in Research Methodology; How to Choose a Sampling Technique for Research. International Journal of Academic Research in Management, 5(2), 18-27.

Torrico, B. H., Frank B. \& Taverra, C. A. (2018). Corporate social responsibility in Bolivia: meanings and consequences, International Journal of Corporate Social Responsibility, 3(7), 34-45.

Verma. (2015). Impact of Corporate Social Responsibilities in Modern Business Environment, International Journal of Scientific and Research Publications, 5(2), 1-4.

Wilfred, A., Mbako, J. \& Njoya, E. (2018). Environmental Health Concerns in Cameroon, Online.

WCED. (1987). World Commission on Environment Development, Our common future, Oxford University Press, Oxford.

Yin, R. K. (2014). Case study research: Design and methods (5th Ed.). Thousand Oaks, CA: Sage

Zalaghi, H. \& Khazaei, M. (2016). The Role of Deductive and Inductive Reasoning in Accounting Research and Standard Setting, Asian Journal of Finance \& Accounting, 8(1), 23-37.

Visser, W. (2006). Research on Corporate Citizenship in Africa: A Ten-Year Review (1995-2005).

Visser, W. \& Macintosh, A. (1998). A Short Review of the Historical Critique of Usury. Accounting, Business \& Financial History, 8(2), 175-89. 